\title{
Religión, política, espacio público y laicidad en el Uruguay progresista
}

Religion, politics, public space and secularism in the progressist Uruguay

\author{
Juan Scuro* \\ *Universidad de la República - Montevideo, Uruguay \\ Posdoctorado en curso (becario CAP) \\ juanscuro@gmail.com
}




\title{
Resumen
}

En las últimas décadas, y muy especialmente acentuado en los años más recientes, el tema de la laicidad ha reemergido con ímpetu en Uruguay. Las controversias y los principales actores no son nuevos (Iglesia Católica, Masonería), pero los episodios que obligan a problematizar el concepto de laicidad se suceden unos tras otros, sirviendo de piezas de un tenso tablero de moralidades, valores y prácticas en disputa. La llegada de Tabaré Vázquez al gobierno nacional en 2005, su sucesión por José Mujica en 2010, y su regreso a la presidencia en 2015 son el hilo conductor de los varios episodios que se describen en este texto, incluyendo disputas por instalación de símbolos religiosos en el espacio público y el relato de las últimas alianzas entre religión y política en el Uruguay.

Palabras clave: religión; espacio público; laicidad; Uruguay.

\begin{abstract}
In recent decades, and especially marked in recent years, the issue of secularism has re-emerged with impetus in Uruguay. The controversies and the main actors are not new (Catholic Church, Masonry), but the episodes that force to problematize the concept of secularity happen one after another, serving as pieces of a tense board of moralities, values and practices in dispute. The arrival of Tabaré Vázquez to the national government in 2005, his succession by José Mujica in 2010, and his return to the presidency in 2015 are the thread of the various episodes described in this text, including disputes over the installation of religious symbols in the public space and the account of the last alliances between religion and politics in Uruguay.
\end{abstract}

Keywords: religion; public space; secularism; Uruguay. 


\section{Introducción ${ }^{1}$}

Resulta un lugar común referirse al Uruguay con adjetivos que lo particularizan y distinguen de sus vecinos respecto a los vínculos entre Religión y Política. Suele no dudarse en ver al Uruguay como un país laico por excelencia, de un modo un tanto más radical que sus vecinos directos. Se recurre con facilidad a hechos históricos tempranos en el desarrollo del proceso de secularización uruguayo. Se afirma que el peso de la Iglesia Católica y su relevancia política en el Uruguay es menor que la de otros países de la región. En cambio, la masonería, el jacobinismo, el anticlericalismo, habrían sido elementos de peso en la construcción del Estado-nación moderno. Hay cierto consenso en el ámbito académico (más allá de evidentes matices) de que al Uruguay lo ha caracterizado una especie de laicismo radical, producto de un fuerte proceso de secularización, incluso entendido como jacobino, al menos históricamente (Asiaín, 2010; Caetano, 2013; Caetano; Geymonat, 1997; Da Costa, 1999; 2009; Guigou, 2003, 2006; Monreal, 2016a, 2016b).

Hechos relevantes en el proceso de secularización y laicización ocurrieron en el período que comprende desde el último cuarto del siglo XIX a las dos primeras décadas del XX. El batllismo es tomado como marco jurídico-histórico significativo ya que fue en su primera etapa donde se implementaron acciones como la sanción de la ley, de 1906, que determinó que se retiraran los crucifijos del Hospital de Caridad, o la puesta en vigencia de una nueva Constitución de la República, en 1919 (votada en 1917), en la que quedaban definitivamente separadas la Iglesia Católica del Estado y donde se hace explícito que "todos los cultos religiosos son libres en el Uruguay" y que "el Estado no sostiene religión alguna" (Art. $\left.5^{\circ}\right)^{2}$

Gerardo Caetano (2013, p. 118) se refiere, para ese período histórico fundante del Estado moderno, al proceso de "naturalización de una visión radical de la laicidad y dice "radical" por dos razones: la primera, por una "marginalización

1 Quiero agradecer los importantes comentarios que he recibido de los evaluadores de este artículo. Su lectura atenta y crítica me ayudó mucho a observar las limitaciones del texto sometido a revisión. Sin duda, este es un mejor artículo gracias a esos aportes.

2 Ver Caetano y Geymonat (1997). 
institucional de lo religioso y su radicación paulatina en la esfera privada", y la segunda, por la adopción de "posturas oficiales fuertemente críticas respecto de la religión institucional hegemónica (en esta caso la Iglesia Católica), unido a 'una transferencia de sacralidad de lo religioso a lo político', que derivó en la conformación de una suerte de 'religión civil'" (Caetano, 2013, p. 118). Estos aspectos, afirma el historiador, se constituyeron como centrales del proceso de secularización uruguaya. A su vez, Caetano (2013, p. 120) utiliza la tipología elaborada por Micheline Milot sobre laicidad (separatista, anticlerical, autoritaria, de fe cívica, y de re conocimiento) para argumentar que "el modelo clásico de laicidad en el caso de la historia uruguaya sería una mezcla de los prototipos 'separatista', 'anticlerical' y de 'fe cívica'”.

Por otra parte, pero siguiendo con las tipologías, Néstor da Costa (2009) plantea tres categorías de las posturas sobre la laicidad por parte de diferentes actores en Uruguay: una posición intransigente, una posición plural, y una tercera posición negadora. La posición intransigente, dice Da Costa (2009, p. 146) se caracteriza "por un prejuicio antirreligioso, refiriéndose a lo religioso en términos de oscurantismo e ignorancia, negando cualquier tipo de reconocimiento a lo religioso en el sistema educativo público, y manifestando un claro prejuicio anticlerical". La posición plural, afirma el sociólogo:

expresa la necesidad de mantener separados los asuntos confesionales del Estado y lo educativo y reconoce, respeta y valora las distintas expresiones de religiosidad de sus conciudadanos. En el ámbito educativo, entiende que se debe salir de una actitud de ignorancia y presindencia de lo religioso como fenómeno social, y acepta la inclusión de lo religioso sin que ello implique ningún grado de confesionalización. (Da Costa, 2009, p. 147).

Finalmente, la tercera postura planteada por Da Costa (2009, p. 147) es la posición "negadora de la laicidad, en el sentido de reclamar la inclusión de cierta confesionalidad en el espacio público; se trata, así, de un posición cercana al antimodernismo". En Uruguay, sostiene Da Costa (2009, p. 152), "el desplazamiento de lo religioso en forma radical hacia la esfera privada creó una suerte de religión civil del Estado".

A su vez, el antropólogo Nicolás Guigou, luego de publicar, precisamente La nación laica: religión civil y mito praxis en el Uruguay (Guigou, 2003), dice: 
la privatización de lo religioso en Uruguay -parte de los efectos de un radical proceso de secularización y laicización ocurrido desde mediados y finales del siglo 19 hasta aproximadamente la década de los “30 del siglo 20-y la elaboración de una religión civil "jacobina", sustitutoria y homogeneizadora, matrizó sin duda la conformación de la nación en cuestión. (Guigou, 2006, p. 46).

Todo indica que estamos, en Uruguay, frente a un modelo de laicidad de tipo "republicano", siguiendo la tipología propuesta por Maclure y Taylor (2011) cuando proponen pensar dos modelos o tipos ideales de laicidad, una laicidad que llaman "republicana" y una laicidad "liberal-pluralista". Volcada hacia el tipo "republicana" se encontraría cierto "fetichismo de los medios", es decir, una suerte de confusión entre los fines (que identifican con "el respeto de la igualdad del valor moral de los ciudadanos y la protección de la libertad de conciencia") y los medios de la laicidad ("separación de lo político y lo religioso y la neutralidad religiosa del Estado") (Maclure; Taylor, 2011, p. 44).

Ahora bien, si, como podemos ver, el consenso sobre el carácter fuertemente secularizador, de laicismo radical y de construcción de religión civil en el Uruguay parece claro, también es cierto que el consenso continua afirmando que en las últimas décadas el Uruguay ha acompañado los procesos regionales y globales de desprivatización de lo religioso y de retorno de lo religioso al espacio público. Así lo muestran, por ejemplo, los trabajos antes mencionados de Caetano y Da Costa. Siguiendo la perspectiva crítica de José Casanova respecto a la teoría de la secularización (cuyos replanteos pueden verse en Casanova, 2006), ambos autores se suman a un revisionismo de las principales tesis de la teoría de la secularización a la luz de los hechos empíricos que se observan en nuestras sociedades (Caetano, 2013; Da Costa, 2008). En esta dirección de visibilidad pública de lo religioso, Guigou (2006) llamaba la atención respecto al proceso de gradual presencia pública del neopentecostalismo en Uruguay y su "neopentecostalización" de la lengua política.

Más recientemente, ha sido publicado un importante volumen con detalles del proceso de secularización y laicización y revisiones a partir de los hechos de las últimas décadas, que incluye el período que inicia en 2005 con la asunción de Tabaré Vázquez como presidente de la República y la llegada del Frente Amplio al gobierno nacional (Caetano et al., 2013), momento a partir del cual nos centraremos en este artículo. 
Las publicaciones de Néstor da Costa (2009) y Gerardo Caetano (2013), muestran con varios ejemplos el revuelto campo de disputas y cambios en torno al tema de las relaciones entre religión y política y las actualizaciones en el debate en torno a la laicidad. Los ejemplos son muchos. Para unos serán muestra de una apertura de la laicidad quizá hacia el polo "liberal-pluralista" sugerido por Maclure y Taylor (2011) que podríamos hacer coincidir con la posición "plural" propuesta por Da Costa (2009). Para otros, los episodios que se van sucediendo responden a una clara avanzada católica y ponen a "la laicidad en peligro" (Pioli, 2016).

Uruguay está atravesando un interesante momento histórico en el que estas discusiones muestran sus múltiples aristas. Este texto pretende contribuir a la visualización de las mismas, relatando algunos episodios recientes significativos. Para ello, parto de la llegada de Tabaré Vázquez al gobierno en 2005 y narro algunos hechos tomados de la literatura hasta aquí mencionada, de los medios de prensa, de versiones taquigráficas del parlamento, de pronunciamientos hechos públicos a través de internet y de la observación directa por medio de mi propia participación en algunos casos concretos. Si la laicidad es un concepto tan polisémico y en tan fuerte disputa en Uruguay, y si para los distintos actores, tanto académicos como políticos y/o sociales la temática es tan relevante y tan frecuentemente puesta sobre la mesa de discusión, pues es un tema altamente sensible para la sociedad en su conjunto, el relato de los hechos que muestro a continuación se justifica porque ellos han despertado, de diferentes modos, viejas y nuevas discusiones y tensiones intrínsecas a la vida democrática del Uruguay. Varios de los hechos que aquí se describen ya fueron abordados en las publicaciones mencionadas. El propósito aquí es avanzar sobre hechos posteriores a esas publicaciones, que continúan trazando una secuencia de episodios que narran y escenifican de manera ejemplar las formas en que se vive la laicidad, la secularización y las relaciones entre religión y política en Uruguay.

\section{Vázquez, Iglesia Católica y Masonería}

En el año 2005 accedía por primera vez al gobierno nacional el Frente Amplio (FA), coalición de partidos de izquierda fundada en 1971, y Tabaré Vázquez 
asumía la Presidencia de la República (2005-2010). A su mandato le siguió el del también presidente por el Frente Amplio, José Mujica (2010-2015), quien fuera sucedido, nuevamente, por Tabaré Vázquez para el período 2015-2020. En este período de tres lustros los vínculos entre religión y política, religión y espacio público han mostrado interesantes facetas, que incluye presencias inéditas de religiosos en el parlamento, disputas por símbolos religiosos en el espacio público, alianzas político-religiosas, y una mayor presencia y debate público de las temáticas de la laicidad y las relaciones entre las esferas políticas y religiosas, debates visibles en los medios de comunicación, en el ámbito académico y político.

En los meses inmediatos a la asunción de Tabaré Vázquez como presidente de la República, el $1^{\circ}$ de marzo de 2005, sucedieron algunos episodios que muestran un nuevo escenario para los vínculos entre religión y política en el Uruguay. En un encuentro que mantuvieron el presidente Vázquez con el entonces arzobispo de Montevideo, Nicolás Cotugno, se resolvió el apoyo por parte del gobierno al pedido de Cotugno, de trasladar una estatua del entonces recientemente fallecido Juan Pablo II, desde el interior de una iglesia hacia los pies de un cruz ubicada en la intersección de importantes avenidas de la zona céntrica de la ciudad de Montevideo. Juan Pablo II había visitado el Uruguay en 1987, y en aquel entonces fue montada de forma provisoria una gran cruz sobre Bvar. Artigas, a pocos metros de donde se ubica el Obelisco a los Constituyentes. Lo que originalmente era una instalación provisoria, acabó, tras arduas discusiones parlamentarias, siendo permanente. La situación alcanzó al parlamento nacional que, tras varios meses de discusión, sancionó la ley 15.870, en la que se dispone "que la cruz erigida con motivo de la visita a la ciudad de Montevideo del papa Juan Pablo II, sea mantenida en su emplazamiento original y con carácter permanente, en calidad de monumento conmemorativo de dicho acontecimiento" (Uruguay, 1987). ${ }^{3}$

La denominada "cruz del papa" quedó allí en forma definitiva. Este episodio ha sido analizado por Gerardo Caetano (2003) y es comúnmente repetida su significancia como momento a partir del cual se daba inicio a una nueva etapa

3 Todo el trámite parlamentario y sus correspondientes versiones taquigráficas pueden verse en http://www.parlamento.gub.uy. 
respecto a las formas de entender la laicidad en el Uruguay, en camino hacia una desprivatización de lo religioso. ${ }^{4}$ La discusión y polémica no fueron sencillas, pero finalmente, la cruz acabó permaneciendo erecta. La iglesia en la que se encontraba la estatua de Juan Pablo II que se pidió trasladar hasta esta cruz, no dista más de doscientos metros de donde se encuentra la "cruz del papa". La estatua estaba, hasta mayo de 2005 , en el interior del predio de la iglesia, fuera del edificio pero dentro del predio de la iglesia. El 2 de Mayo de 2005, dos meses después de la asunción de Tabaré Vázquez como presidente de la República y uno después del fallecimiento del papa, fue colocada una placa conmemorativa al lado de la recientemente trasladada estatua de Juan Pablo II a los pies de la "cruz del papa", en plena avenida Bvar. Artigas. El traslado había sido aprobado por unanimidad, pocos días antes, en la Junta Departamental de Montevideo, legislativo capitalino. La placa conmemorativa que fue presentada aquel día en la nueva ubicación de la estatua junto a la cruz fue develada en conjunto por el arzobispo Nicolás Cotugno y la señora María Auxiliadora, esposa de Tabaré Vázquez, reconocidamente católica.

El hecho, por supuesto, no pasó desapercibido para sectores de la sociedad uruguaya que se manifestaron públicamente expresando el rechazo a esta medida. Entre ellas, estuvo la expresión de insatisfacción de parte de la Federación de Iglesias Evangélicas del Uruguay, que consideraron el hecho "una violación al espíritu de respeto en el marco de la laicidad". ${ }^{5}$

El 14 de julio de 2005, a los cuatro meses del inicio de su primer mandato, dos meses después de los hechos antes narrados y en una fecha tan significativa, el presidente Tabaré Vázquez, de reconocida filiación masónica, visitó la Gran Logia de la Masonería del Uruguay. El tema de su discurso en ocasión de la visita fue, precisamente, la laicidad, un tema, en palabras del propio Vázquez, “importante, apasionante y a menudo polémico que sin duda no es nuevo en

4 "Ha surgido renovada evidencia sobre una cierta erosión de la tradicional percepción de Uruguay como 'país laico' y ‘sociedad secularizada' sostenían Caetano y Geymonat ya en 1997 y ponían como hito para el debate público sobre el tema la instalación de la "cruz del papa" tras su visita en 1987.

5 Carta al presidente de la República y entrevista al presidente de la Federación de Iglesias Evangélicas del Uruguay, publicadas en Radio Centenario el 3 de mayo de 2005 (Radio Centenario, 2005). 
este ámbito ni es nuevo en el país". ${ }^{6}$ La pregunta con la que inició su intervención apuntó a reflexionar en torno a de qué es que se está hablando, cuando se habla de laicidad, y lanzó su visión sobre el tema: "la laicidad es un marco de relación en el que los ciudadanos podemos entendernos desde la diversidad pero en igualdad. La laicidad es garantía de respeto al semejante y de ciudadanía en la pluralidad. O dicho de otra manera: la laicidad es factor de democracia".

Continuando esta línea argumentativa Vázquez sugirió que la laicidad está entonces directamente asociada a la democracia y, por lo tanto, a la dignidad humana, la autonomía y la capacidad de decisión. Sostuvo Vázquez: "la laicidad no inhibe al factor religioso. ¡Cómo va a inhibirlo si, al fin y al cabo, el hecho religioso es la consecuencia del ejercicio de derechos consagrados en tantas declaraciones universales y en tantos textos constitucionales!!".

Pasando de lo formal a develar más específicamente su involucramiento en la temática y sugiriendo mensajes hacia los diferentes actores que intervienen en la escena local, Vázquez expresó:

La laicidad no es incompatible con la religión; simplemente no confunde lo secular y lo religioso. "Si fuera tan simple no habría tanta polémica", estarán pensando en este preciso instante varios de ustedes. Es verdad: la polémica existe. Pero, jcuidado! Una cosa es la polémica y otra es el griterío. Una cosa es debatir sobre la laicidad en tanto marco siempre perfectible de relación entre los ciudadanos y otra, bien diferente y deplorable por cierto, es gritar en nombre de la laicidad o en contra de ella. Digo esto porque en nombre o en contra de la laicidad se grita mucho. También se calla mucho, justo es decirlo; en unos casos pretendiendo fortalecerla y en otros intentando exactamente lo contrario. Y digo también que quienes tanto gritan o tanto callan respecto a la laicidad no hacen más que vulnerarla en lo que ella significa como factor de democracia.

La contundencia de sus palabras traen al centro a una laicidad a la que Vázquez quiere alejar del "griterío", entendiendo que tanto esto como "lo que se calla"

6 Discurso de Tabaré Vázquez en la Gran Logia de la Masonería, 14 de julio de 2005 (Presidencia, 2005). 
atentan contra la laicidad misma. En un doble movimiento aleja a la laicidad de estos "límites" y se posiciona en el "centro" de un debate en el que existen diferentes posturas, incluso dentro de la masonería, a quienes está hablando y proponiendo su visión y posición sobre el tema, en el inicio de su mandato como presidente de la República e invitándolos a que "lo que queda por hacer en materia de laicidad hemos de hacerlo entre todos, cada uno desde su propia identidad, y en diálogo con un proyecto de país con el cual todos podamos sentirnos identificados y en cuya construcción todos nos involucremos"?

De esta forma comenzaba entonces el primer gobierno de Vázquez, dando importantes signos a la Iglesia Católica y la Masonería, ambas instituciones muy caras al presidente.

Si la instalación definitiva de la "cruz del papa" dio inicio a la "erosión de la tradicional percepción de Uruguay como 'país laico' y ‘sociedad secularizada'” (Caetano; Geymonat, 1997), los gestos mencionados del presidente Tabaré Vázquez acabaron poniendo definitivamente al tema de la laicidad y lo religioso en el centro de la atención. El interés público por esta temática queda evidenciado en la proliferación de actividades académicas al respecto, presencia del tema en los medios de comunicación y generalización del debate.

\section{Afroumbandistas y Frente Amplio}

Tabaré Vázquez, antes de ser presidente de la República, fue intendente de Montevideo, (1990-1994). En el último año de su mandato, la Junta Departamental de Montevideo aprobó la instalación de una estatua en honor a Iemanjá, solicitud iniciada por agrupaciones afro-umbandistas lideradas por el pai Armando Ayala. Siete años después de haber quedado definitivamente instalada la "cruz del papa" en la intersección de importantes avenidas de la zona céntrica de Montevideo, Iemanjá encontraba su lugar en otro valorado espacio de la ciudad: la Rambla de Parque Rodó. Tanto Tabaré Vázquez y el Frente Amplio como los practicantes de las religiones de matriz africana necesitaban apoyos recíprocos, ambos en constante incremento de legitimidades y adhesiones. De

7 Discurso de Tabaré Vázquez en la Gran Logia de la Masonería, 14 de julio de 2005 (Presidencia, 2005). 
forma paulatina, las celebraciones públicas de cada 2 de febrero en honor a Iemanjá fueron ganando visibilidad y concurrencia, principalmente en la Playa Ramírez, donde está ubicada la estatua a Iemanjá. La celebración fue ganando legitimidad y atracción de curiosos de forma permanente, en buena medida impulsado por los esfuerzos del pai Julio Kronberg y su esposa, mãe Susana Andrade, fundadores del grupo Atabaque en 1997, de la Institución Federada Afroumbandista del Uruguay (IFA), en 1999 y de reconocida trayectoria religiosa y política desde el Frente Amplio. Kronberg es, desde 2006, Director de Atención a la Diversidad Cultural de la Intendencia de Montevideo. Andrade, hija de pastores evangélicos que conoce luego la religión Umbanda por medio de su esposo, asumió en 2015 una banca en el parlamento como diputada suplente (FA), con activa participación legislativa.

Iemanjá hace más de dos décadas que contempla el mar en la playa Ramírez del Parque Rodó, ${ }^{8}$ un barrio donde se ubica el parque de mismo nombre y donde cada 2 de febrero multitudes provenientes de todo el país (y del extranjero) hacen suya la playa para expresar sus deseos a la orishá de los mares, 0 simplemente, para curiosear. La fiesta popular fue aumentando su concurrencia y con ella, también su introyección por parte de un importante segmento de la población, al mismo tiempo que su espectacularización. En los últimos años, parecería ser que muchos importantes impulsores de la festividad pública del 2 de febrero en la playa Ramírez han ido optando por expresar su vínculo con su religiosidad en otros lugares o momentos del día, escapando un poco de la multitud que elige concurrir a la playa Ramírez a partir de la puesta del sol. En algunas ediciones de esta celebración abierta ha habido presencia de manifestantes de diferentes segmentos religiosos cristianos y de manifestantes en defensa de los animales, en reclamo de los sacrificios animales celebrados en algunos templos de religiones de matriz africana. Dos puntos han llamado la atención por parte de diferentes colectividades. Ambas relacionadas en diferente grado a los vínculos que serían deseables entre "religión" y "política". Por un lado, como vimos, la perseverancia de grupos afroumbandistas como Atabaque, fundado

8 El parque y el barrio llevan el nombre precisamente de José Enrique Rodó, quien adjetivara como jacobinismo, en 1906, el episodio de la "expulsión de los crucifijos" provenientes de sus filas batllistas, lo cual, como muestra Caetano, fuera también el inicio de la separación de Rodó con el batllismo (Caetano et al., 2013). 
en 1997 por los mencionados Julio Kronberg y Susana Andrade (con una lista específica dentro del Frente Amplio, la 7777) han contribuido a la construcción de una plataforma de acción en pro de la legitimidad y visibilidad de este segmento religioso. En lo que respecta a la especificidad de la celebración pública de la fiesta a Iemanjá, cada 2 de febrero, cabe destacar la obtención de diferentes declaraciones de interés ministerial y municipal. En diferentes ocasiones la celebración del 2 de febrero ha sido declarada de interés por el Ministerio de Educación y Cultura y para el Ministerio de Turismo y Deportes, así como para la Intendencia de Montevideo. Este tipo de acercamiento del Estado a un segmento religioso específico, manifestado en forma de apoyo a una celebración particular, no ha dejado de ser visto con sospecha y mal gusto por parte de los sectores más ortodoxos en el monitoreo de la laicidad. En el entendido de una laicidad donde el Estado es absoluto neutral en materia religiosa, el hecho de que diferentes órganos del poder ejecutivo y del gobierno capitalino hayan hecho explícito su apoyo a la celebración del 2 de febrero es visto como una acción indebida, que atenta contra la laicidad, mostrando tal vez cierto "fetichismo de los medios" a los que se refieren Maclure y Taylor (2011) respecto a los regímenes de laicidad. Por otra parte, es recurrente también, entre las voces más críticas en torno a la celebración de Iemanjá en el espacio público, el notorio hecho de que, en buena medida, la celebración consiste en la realización de ofrendas (frutas, velas, bebidas, alimentos, barcas, imágenes) que una vez terminada la festividad, quedan en forma de residuos, por varios días, a lo largo de toda la franja costera.

En "La laicidad en peligro" Ulises Gastón Pioli recoge varios intercambios de opiniones que circularon a través de las "Cartas al Director" del semanario Búsqueda respecto a "Iemanjá y la laicidad" como se titula una de esas cartas recogidas por Pioli, firmada por Francisco Faig. Varios argumentos de diferente orden son accionados en esos intercambios. Por ejemplo, la carta de Faig dice, “Todos los montevideanos, creyentes o no en Iemanjá, financiarán indirectamente ese culto, ya que con sus impuestos pagarán una jornada especial de limpieza municipal en las playas" (cf. Pioli, 2016, p. 99).

Las críticas han sido varias y, en el caso de Montevideo, la Intendencia ha ido desarrollando estrategias para limpiar las playas a la brevedad posible. Con ánimo de disminuir críticas al mínimo posible, se ha visto, por ejemplo, en la última edición de la celebración de Iemanjá, un fuerte énfasis (especialmente 
hecho público por Susana Andrade) de construir las barcas con materiales biodegradables y naturales y no con la clásica espuma sintética con la que suelen construirse. En esta dirección de construir un discurso alineado con un cuidado del medio ambiente, Andrade ha expresado que el lema de la última celebración era justamente "pedir perdón a la naturaleza". Este discurso parece menos combativo que el utilizado por Andrade en algunos pasajes sobre la celebración de Yemanjá a los que hace referencia en su libro Entre la religión y la política donde muestra el apoyo explícito de la intendencia de Montevideo y la presencia del propio intendente en la celebración (Andrade, 2009, p. 69).

\section{Evangélicos Parlamentarios}

La presencia de líderes religiosos en el parlamento nacional resulta un significativo reflejo de las alianzas que se fueron llevando adelante entre las esferas de la política y la religión en las últimas décadas. La presencia de Susana Andrade, primera diputada mujer afrodescendiente umbandista por el Frente Amplio, se suma a la de otros religiosos, provenientes del campo evangélico, que también alcanzaron en estos últimos períodos de gobierno bancas en la cámara baja.

Para el mismo período legislativo de Andrade fue también electo por Montevideo el pastor Alvaro Dastugue (Partido Nacional), convirtiéndose en el primer pastor neopentecostal en asumir ese cargo. En el período legislativo anterior (2010-2015), Gerardo Amarilla (Partido Nacional - Iglesia Bautista) asumía como primer evangélico diputado (por el departamento de Rivera), reelecto en el actual período también (2015-2020). Dastugue, pastor de la iglesia Misión Vida Para las Naciones y yerno de su fundador, el argentino Jorge Márquez, y Benjamín Irazábal (también Partido Nacional), electo diputado (2015-2020) por el departamento de Durazno y ex intendente de ese departamento, conforman, junto con Amarilla, la denominada "bancada evangélica". Esto representa un hecho realmente llamativo para la vida política del Uruguay. Tan difícil de imaginar puede haber sido, que Nicolás Guigou, cuando en su artículo ya citado de 2006 hace referencia a la presencia pública del neopentecostalismo en Uruguay, al menos desde la década de 1980, y se refiere a la "neopentecostalización de la lengua política", también afirmaba que "No hay pues bancadas 
evangélicas, ni tampoco diferentes nominaciones del universo pentecostal disputando posiciones en la arena política" (Guigou, 2006, p. 51) lo cual muestra los importantes cambios que se sucedieron en los últimos años entre este ámbito religioso y el político.

Gerardo Amarilla presidió en su momento la cámara de diputados y su asunción como tal no estuvo ausente de importantes críticas por parte de sectores tradicionalmente laicistas, que argumentaban la dificultad de este para asumir sin reparos la presidencia de la cámara, dada su conocida filiación a una iglesia evangélica y sus dichos anteriores sobre la superioridad de la ley de Dios respecto a la República. Amarilla había afirmado en reiteradas ocasiones en diferentes medios que él se proponía respetar la ley si no contradice la palabra de Dios. Su filiación evangélica y afirmaciones sobre la ley de Dios fueron argumentos de desconfianza por parte de algunos legisladores que expresaron sus reparos en que Amarilla asumiera temporalmente la presidencia de la cámara. Algunos diputados le recordaron a Amarilla la tradición laica del Estado uruguayo y que el parlamento no podía transformarse en un lugar de proselitismo religioso. Fernando Amado, diputado del Partido Colorado y autor de varios libros sobre religión y política, masonería, opus dei etc., votó en contra de la asunción de Amarilla como presidente de la cámara en su momento. En su discurso de asunción Amarilla declaró que iba a respetar la laicidad.

En buena medida, uno de los ejes de los discursos de los parlamentarios evangélicos (aunque con diferencias, me refiero principalmente a Dastugue) han apuntado a una clara arremetida contra el avance de la "agenda de derechos" que se pudo observar durante el gobierno de José Mujica. Fue en el período de gobierno de Mujica que el parlamento nacional sancionó al menos tres leyes que afectaron las sensibilidades de algunos sectores que reaccionaron con miras a la modificación de las mismas. Se trata de la aprobación de las leyes: 18.987, de octubre de 2012, que despenaliza la interrupción voluntaria del embarazo; la ley 19.075 , de mayo de 2013 , que aprueba el matrimonio civil entre personas del mismo sexo; y la ley 19.172, de diciembre de 2013 , que regula el mercado de cannabis y lo hace accesible a la población de forma legal, suministrado por el Estado. Cabe recordar que en 2008 el parlamento ya había aprobado una ley (18.426) que incluía la posibilidad de la interrupción voluntaria del embarazo, cuyos artículos al respecto fueron vetados por el entonces Presidente de la República, Tabaré Vázquez. 
El escenario de avance en la agenda de derechos impulsada por el Frente Amplio y organizaciones sociales generó la reacción conservadora y la movilización política y estratégica de, por ejemplo, Alvaro Dastugue, quien, a través de una alianza con la entonces diputada y actual senadora del Partido Nacional, Verónica Alonso, alcanzó la banca de diputados para el actual período legislativo (2015-2020). Dastugue, yerno del fundador de Misión Vida para las Naciones, vive en un de los varios hogares Beraca comandados por esta iglesia, donde se internan personas en situación de vulnerabilidad social y usos problemáticos de drogas. Fue esta estructura de los hogares Beraca lo que Dastugue puso a disposición de Verónica Alonso con el objetivo de la promoción política de ambos, resultando electos, ella senadora y él diputado. Actualmente existen algunos conflictos en esta alianza que están en el ámbito de la justicia y que involucra deudas a las que se adjudican recíprocamente la responsabilidad del pago entre ambos, la senadora y el diputado.

Pero lo que me interesa apuntar aquí no es la interna de estos asuntos sino el hecho de la existencia de alianzas de cierto modo novedosas para la tradición laica uruguaya. Tenemos de este modo planteado un escenario de fervientes discusiones e intercambios de perspectivas respecto al nuevo lugar de lo religioso en la escena pública uruguaya. A los actores tradicionales como la masonería o la iglesia católica, se sumaron, en lo que refiere al uso concreto de los espacios públicos, los sectores afroumbandistas. Actores más recientes en esta superposición entre religión y política son los ejemplos mencionados de los diputados evangélicos y su accionar concreto en búsqueda de una "moral cristiana" que se funda en el modelo de familia tradicional, patriarcal, heterosexual y "sin drogas".

Las moralidades, identidades y libertades están en una pujante disputa política en el Uruguay. El marco interpretativo de la laicidad es un eje importante por el que transitan y se manifiestan los intentos de materializar estas pujas por parte de los diferentes sectores involucrados. El ámbito político en sentido estricto (partidario) es uno de ellos. La presencia de símbolos religiosos en el espacio público es otra evidente forma de hacer visibles los procesos de identificación y disputa. El ámbito de la educación es otro espacio privilegiado de encuentro de fuerzas. Las formalidades institucionales son monitoreadas con sigilo y varios movimientos hacen disparar las alarmas de la laicidad en el Uruguay. Esto no es una novedad en este país, pero está actualmente en un punto de especial interés. 


\section{Las laicidades del Uruguay}

La Iglesia Católica, tras más de tres lustros de conducción por parte del anterior arzobispo Nicolás Cotugno, ha dado, en los últimos años y luego de la designación del actual arzobispo Daniel Sturla, claras intenciones de no querer quedarse atrás en la disputa por el espacio público. Las primeras señales de Sturla fueron dadas al reunirse, el nuevo arzobispo y cardenal (nombrado como tal en 2014 y 2015 respectivamente), con representantes de colectividades LGBT del Uruguay, donde aquel pidió disculpas a estos por posibles acciones de la Iglesia Católica que pudieran haber herido a esta comunidad. De esta forma, no solo intentaba aproximaciones estratégicas sino también tomar distancia de su antecesor, duro crítico de cualquier conducta sexual que escapara a la heteronormatividad. Era el inicio de una nueva estrategia de comunicación y presentación pública de la Iglesia Católica en Uruguay. Una campaña de "recristianización", como fue expresado por autoridades católicas en diferentes oportunidades.

Los movimientos de la Iglesia Católica son observados con atención por los contralores de la laicidad en el Uruguay. Episodios recientes que involucran a las cúpulas militares y autoridades del gobierno en relación con la Iglesia Católica fueron foco de atención.

El 19 de Junio de 2014, cuatro meses después de la asunción de Sturla como arzobispo de Montevideo, tuvo lugar un hecho inédito en el Uruguay. Cada 19 de Junio se celebra en las escuelas y liceos (públicos y privados) el denominado "juramento a la Bandera", tal como lo establece la ley 9.943, de 1940. El artículo 28 de dicha ley establece la obligatoriedad de prestar juramento de fidelidad a la Bandera Nacional en acto público y solemne, y agrega: "todos los Institutos privados de enseñanza secundaria y profesional, dispondrán que en sus respectivos locales los alumnos presten ese juramento en idénticas condiciones" (Uruguay, 1940). El 19 de Junio de 2014, sin embargo, estudiantes de un colegio Marista realizaron el acto de juramento de la Bandera Nacional, no en "sus respectivos locales" y "en idénticas condiciones", sino en la Catedral de Montevideo, en acto presidido por el arzobispo Sturla y, como denuncia la Asociación Civil 20 de Septiembre (2014), en presencia no solamente de la Bandera Nacional sino también de la bandera del Estado Vaticano. El hecho trascendió en los medios de comunicación.

Por otra parte, hubo otras denuncias que desencadenaron un pedido de informes en el parlamento por parte del senador del Partido Colorado, 
Ope Pasquet (batllista y masón) que trascienden a la Iglesia Católica en sí misma y apunta a jerarcas del gobierno y militares. Veamos:

Hacia fines de 2014, fue creado el "Departamento de Asuntos Religiosos" en el Ejercito Nacional y de ese departamento se adjudicó la dirección al coronel retirado y sacerdote católico Genaro Lusararian. El propósito del Departamento, según expresado por las autoridades, era poder brindar asistencia espiritual a quienes así lo solicitaran. El Director Nacional de Sanidad de las Fuerzas Armadas en ese entonces era Guido Manini Ríos, de tradición colorada (riverista, adversarios del batllismo dentro del Partido Colorado). El 23 de septiembre de 2015 (aniversario de la muerte del prócer José Gervasio Artigas) fue finalmente inaugurada una capilla en el Hospital Militar. La inauguración contó con la presencia y bendición del arzobispo Sturla. De la misa participó también la señora María Auxiliadora, esposa de Vázquez. Sin duda, un hecho interesante del que Emerson Giumbelli tendría elementos para comparar con sus estudios sobre ámbitos ecuménicos en espacios públicos en Brasil. Su pregunta, ¿qué es un ambiente laico? es de profunda relevancia y difícil respuesta (Giumbelli, 2013). Al comienzo de ese año, 2015, Guido Manini Ríos se había convertido en el Comandante en Jefe del Ejército. Según informaron diferentes medios de prensa en ese momento, su nombre no era el más probable para ocupar ese cargo ya que no era de la confianza del presidente electo Tabaré Vázquez pero sí de quien se desempeñaba como Ministro de Defensa desde el gobierno de Mujica y que lo seguiría haciendo en el actual de Vázquez, el ex tupamaro Eleuterio Fernández Huidobro.

Finalmente, el 18 de Mayo de 2016, otro episodio involucrando al Comandante del Ejército y a la Iglesia Católica tuvo repercusión pública. El 18 de mayo de cada año se celebra el "Día del Ejército". En esa ocasión, se celebró una misa en la Catedral de Montevideo a la que asistió Manini Rios uniformado, participando activamente de la ceremonia religiosa. Las controversias giraron en torno a la utilización o no de los medios formales del Ejército para invitar a la celebración religiosa, la conveniencia de la participación en ese acto uniformado y en representación del Ejército y una serie de otros aspectos denunciados en un pedido de informes parlamentario.

La sumatoria de estos episodios hicieron que el senador Ope Pasquet iniciara un pedido de informes vía parlamentaria. Esto derivó en la citación del Comandante del Ejército, Guido Manini Ríos, y del Ministro de Defensa, 
Eleuterio Fernández Huidobro, ante la Comisión Parlamentaria de Constitución, Códigos, Legislación General y Administración. Esta comisión está integrada, entre otros representantes, por Susana Andrade y Ope Pasquet. La versión taquigráfica de la sesión que mantuvo la Comisión con las autoridades citadas, el 15 de junio de 2016 (disponible en http://www.parlamento.gub.uy) no tiene desperdicio. Allí puede apreciarse, como también veremos más adelante en otro ejemplo, el encuentro de miradas sobre la laicidad y la performance del encuentro de narrativas.

Luego de mencionar los ejemplos, el senador Pasquet, sostuvo:

Entonces, mirando el panorama en su conjunto, uno tiene la impresión de que hay una aproximación notoria entre las Fuerzas Armadas, en particular el Ejército, y la Iglesia Católica, a través de todos estos hechos que vengo señalando. Y francamente me preocupa que eso sea así, no por tratarse de una religión en particular; pasaría lo mismo con cualquier religión. El Estado uruguayo es laico y todas sus instituciones deben ser tan laicas como el Estado mismo: no hay previsión que habilite a hacer excepción alguna. Nuestra Constitución no reconoce ninguna excepción en esta materia. (Ope Pasquet).

A su vez, el siguiente orador fue el Ministro de Defensa, Eleuterio Fernandez Huidobro, quien comenzó diciendo que:

fui consultado y soy totalmente responsable de la concurrencia a la misa ofrecida por el señor cardenal Sturla porque, en primera instancia, personalmente no sentí que violaba ninguna laicidad y hasta me pareció que era una retribución, porque él es asiduo concurrente a las ceremonias militares. No se nos ocurre prohibirle la entrada a ningún religioso -aun con sus atavíos que representan a muchas religiones- a ceremonias del Ejército o de las Fuerzas Armadas. (Fernandez Huidobro).

Y tras argumentar con varios ejemplos a favor de su autorización y de los hechos sucedidos afirmó el Ministro: "Laicismo no significa prohibición de la práctica religiosa ni guerra a las religiones".

Llegado el turno del Comandante en Jefe del Ejército, este, luego de expresar su simpatía hacia la laicidad dijo: "quiero expresar que estoy firmemente 
convencido de que el 18 de mayo pasado no se violó la laicidad ni el espíritu del artículo $5^{\circ}$ de la Constitución" y argumentó diciendo que la iniciativa de la misa surgió de parte de algunos militares retirados, que él concurrió a un acto social y no religioso en el que se estaba homenajeando al Ejército, que la comunicación fue de carácter informal y la participación del personal subalterno fue voluntaria, etc. También se refirió a los otros episodios, como la inauguración de la capilla y el Departamento de Asuntos Religiosos, sobre lo cual, sostuvo:

La designación del sacerdote como jefe del Departamento de Asuntos Religiosos obedeció a una situación particular que se estaba dando y que espero que no se siga produciendo. Me refiero a una verdadera expoliación que sufrían algunos internados, quienes se encontraban en un estado de fragilidad total. Venía el hermano no sé cuánto, el pae no sé cuánto, el sacerdote no sé cuánto, el cura no sé cuánto, y se acercaban a estas personas, que generalmente son muy humildes y están solas, y les terminaban sacando plata para ir a rezar y a pedir a Dios que se mejoraran. Era una verdadera vergüenza lo que estaba pasando. (Guido Manini Rios).

La falta de espacio me impide profundizar en las intervenciones que se fueron sucediendo en esta sesión, todas y cada una de ellas, muy elocuentes, pero debo sí, incluir, para finalizar esta sección, las palabras de la diputada Susana Andrade, quien sostuvo:

Compruebo con pesar los prejuicios y la existencia de jerarquías culturales que han vertido en sus conceptos los invitados: el cardenal es el cardenal; el pae es el "pae no sé cuánto". Por cierto que rechazo esa forma despectiva de expresarse: creencias provenientes de pueblos aplastados por las colonias europeas en América, justamente, en nombre de una evangelización que fue genocidio, esclavización, asesinatos en masa de indígenas, de africanos, de lo cual es consecuencia el racismo y la discriminación racial estructural que hoy existe y se percibe, inclusive acá. Lo digo con dolor por esas centenas y millones de almas, cuyos descendientes todavía sufren avasallamiento cultural en nuestra sociedad uruguaya, latinoamericana y caribeña. Pido memoria para esos datos de la realidad, esos hechos incontestables: no debemos olvidarlos, inclusive, en nombre de la convivencia que promueve nuestra Ley General de Educación, $\mathrm{N}^{\circ}$ 18.437, 
cuando define la laicidad inclusiva, a la que tal vez hacía referencia el diputado que me precedió en el uso de la palabra. Se trata de una laicidad que no admite hegemonías y tampoco predominancias, como de alguna forma se ha palpado que existen en el tratamiento que se le da a la religiosidad católica dentro de los establecimientos del Ministerio de Defensa Nacional. (Susana Andrade).

\section{Las balconeras y la Virgen}

En diciembre de 2016, cuando se acercaba la navidad, algunas fachadas de casas montevideanas comenzaron a lucir unas "balconeras" (banderas que se cuelgan en balcones), con los colores papales, una imagen del "nacimiento" en el medio y la frase "Navidad con Jesús". La campaña tuvo bastante repercusión y la cantidad de fieles que se fueron animando a hacer pública su filiación religiosa católica fue en aumento. En los días próximos al 24 y 25 de diciembre llegó a ser incluso algo sorprendente la cantidad de "balconeras" que se podían observar por la ciudad. La más controversial de todas esas balconeras, fue la que se pudo observar en la puerta de la residencia particular del presidente de la República, Tabaré Vázquez (segundo mandato, 2015-2020). La conocida filiación católica de su esposa, María Auxiliadora, habría hecho que la fachada de la residencia de Vázquez luciera, al lado de la bandera de Uruguay que suele observarse en el frente de su domicilio, la balconera de "Navidad con Jesús". Esto, por supuesto, despertó, una vez más, las diferentes voces, contralores de la laicidad en Uruguay. ¿Podía, el presidente de la República, colgar la balconera en la puerta de su casa sin "violar la laicidad"? Hubo posiciones para todas las respuestas posibles.

Otro lugar donde era posible observar varias de estas balconeras era a lo largo de la Rambla de Montevideo. En barrios como Pocitos y Buceo (sobre la rambla) llegó a ser llamativa la presencia de estas balconeras en los frentes de las casas y apartamentos en edificios.

La Rambla de Montevideo es un parque lineal de más de 20 quilómetros de extensión, límite sur de la ciudad de Montevideo, mostrador y lugar de contemplación del Río de la Plata. En esa franja sur, y del centro hacia el este, se concentra la riqueza de los montevideanos. Por el contrario, hacia el norte, aparecen mayores vulnerabilidades. Estar presente en el espacio público del sureste, tiene efectos diferentes a estar presente en el espacio público del norte. 
La Iglesia Católica viene convocando hace varios años a un Rosario de Bendiciones para la Familia, encuentro que se viene realizando cada último sábado del mes de enero, en la Rambla de Buceo. En la edición a la que asistí en enero de 2017, se llevó a cabo una misa a cielo abierto, frente al mar, en el horario de la puesta del sol. Concurrieron varios miles de católicos que se dispusieron (algunos) a confesarse con los varios sacerdotes que se habían dispuesto aquella tarde para ese fin. A los participantes se les entregaba una vela blanca protegida con una pequeña "cajita" de cartón con un Padre Nuestro y un Ave María inscriptos. En un momento las velas fueron encendidas y un enorme rosario formado por globos fue lanzado al cielo. Un gigantesco rosario se pudo ver sobrevolando Montevideo. Entre otras cosas, se podía observar a algún participante de aquel encuentro con carteles con leyendas del tipo: "Sí a la Virgen María en la Rambla".

La Iglesia Católica había iniciado una solicitud para la instalación de una estatua de la Virgen María en la Rambla del Buceo.

Los fieles católicos que se congregan en esa zona de la ciudad y que han traído la imagen de María desde México, apoyados por la avanzada católica que representa la nueva política del actual arzobispo Daniel Sturla, iniciaron un pedido ante los organismos competentes para la instalación definitiva de la estatua de la Virgen María en la Rambla. Este grupo de vecinos habría propuesto a la Intendencia de Montevideo hacerse cargo de los gastos de instalación y mantenimiento de la imagen, según informaron algunos medios de prensa. Y según declaraciones el arzobispo Sturla, la propuesta contó con la autorización de la anterior intendenta de Montevideo, Ana Olivera, también del actual intendente Daniel Martínez y da la Comisión de Patrimonio Cultural de la Nación. La propuesta fue también llevada al órgano territorial de descentralización, llamados municipios, en este caso el denominado $\mathrm{CH}$, de donde habrían surgido guiños positivos a la instalación de María en la Rambla.

Daniel Martínez y Ana Olivera son ambos del Frente Amplio, partido que gobierna el departamento de Montevideo desde 1990, cuando asumía como intendente el dos veces presidente de la República, Tabaré Vázquez.

El intendente Daniel Martínez encaminó la solicitud a la Junta Departamental de Montevideo, órgano legislativo de ese departamento. La Junta está integrada por 31 ediles, de los cuales, en este período legislativo, 18 fueron electos por el Frente Amplio y 13 por la oposición. Entre los integrantes de la Junta 
hay católicos, evangélicos, metodistas, ateos y otras filiaciones religiosas, espirituales o filosóficas. Para que la Junta aprobara la instalación de la estatua de la Virgen María necesitaba 21 votos positivos.

En la sesión de la Junta Departamental de Montevideo del 11 de mayo de 2017, en la que participé desde las barras, se deliberó sobre el tema, que venía siendo acompañado por la prensa y contaba con activa participación de los involucrados, tanto quienes estaban a favor como en contra de la instalación, en la Aduana de Oribe (Rambla del Buceo), de una imagen de María proveniente de México.

Las expectativas de los católicos eran grandes, contaban con diferentes apoyos y tenían fe en que sucedería un milagro que permitiría alcanzar los votos suficientes para que la Virgen María se instalara definitivamente en la Rambla de Montevideo. Las barras de la Junta se colmaron de gente. Estaban mayormente ocupadas por los católicos promotores de la iniciativa, que portaban banderas de Uruguay y de la Virgen María con leyendas de "Sí a la Virgen María". Muchos concurrieron a la sede del legislativo departamental con rosarios, cruces y camisetas con imágenes de María. La mayoría de quienes se podían identificar detrás de estas imágenes eran mujeres, varias que quizá promediaban entre 50 y 60 años, aunque también había varias mayores a esas edades. No había muchos hombres entre los católicos, más que algún "veterano". Todos eran blancos, excepto una mujer con la piel algo más oscura. También había entre ellos una monja y un par de jóvenes mujeres. Los rosarios colgaban de las barras al igual que las banderas. Todos esperaban el milagro. Las barras también eran ocupadas por un puñado de personas que habían pegado sobre las barras unos carteles con la leyenda "NO". No eran muchos, pero se hicieron presentes. Se trataba de miembros de la Asociación Uruguaya de Libre Pensadores, fervientes opositores a la presencia de símbolos religiosos en el espacio público y "defensores de la laicidad".

La sesión transcurría y se podían oír citas y alusiones a José Enrique Rodó, a José Batlle y Ordoñez, a episodios anteriores sobre estos temas, como las instalaciones de la "Cruz del Papa" o de Iemanjá. También se mencionó la estatua de Confucio y surgieron confusiones respecto al carácter religioso o no de ese símbolo. Lo mismo sucedió con relación al monumento que existe sobre la rambla al holocausto del pueblo judío y algunas otras controversiales imágenes para las cuales no había acuerdo respecto al carácter religioso o no de las mismas 
y por lo tanto, del carácter violatorio o no de la laicidad, en todo caso, en una suerte de superposición de los conceptos de laicidad y secularización por parte de los legisladores capitalinos. Se habló de laicidad, de laicidad positiva, de jacobinismo, de anticlericalismo, de batllismo y de los peligrosos cruces entre religión y política e incluso hubo testimonios sobre la paradoja de poder ser colorado, católico y batllista al mismo tiempo.

El Frente Amplio había mandatado a sus ediles a votar unánimemente en contra del proyecto. Católicos votaron en contra. Otros, no necesariamente católicos, que estaban a favor de la instalación tuvieron que votar en contra de todos modos.

La discusión no tuvo desperdicio y mantuvo un relativo buen nivel y clima hasta que hubo que solicitar un cuarto intermedio cuando uno de los ediles favorables a la iniciativa comentó acerca de la incongruencia de la interna frentista de mandatar a sus ediles a votar unánimemente en contra. Se volvió a la calma y continuaron las argumentaciones. Otros entendieron que lo mejor hubiera sido someter el tema a plebiscito.

La prensa hacía su trabajo, tomaba fotos, emitía en directo desde la sesión de la Junta. El clima comenzaba a hacerse cada vez más tenso a medida que se acercaba la hora de la votación. De los 18 ediles electos originalmente por el Frente Amplio, uno es ahora independiente. Ese edil portaba una bandera de la Virgen María en su pupitre. Toda la performance había transcurrido. Todo el mito constructor de la nación había sido narrado. Cada episodio había sido épicamente dramatizado. A cada argumento de los ediles le seguían aplausos, comentarios, críticas y blasfemias desde las barras. Quienes estaban a favor y en contra compartían el mismo reducido espacio de las barras y los gestos de desaprobación de unos y otros eran contemplados por todos. Se vio a algunos en posturas de rezo, esperando el milagro de la Virgen María. Todo fue extraordinariamente bien conducido. Cada uno interpretó sus papeles de memoria, sin necesidad de recurrir al guión.

"Nuestro país es una República laica”; “Cómo podría ofender la presencia de la Virgen María en Montevideo?”; “Si de laicidad se trata sobran las razones para aprobar su instalación"; "Hace décadas que la laicidad está mal comprendida en nuestro país"; "Nos preocupa esa nueva teoría de la laicidad positiva”; "Creo completamente en esa Virgen y creo en Dios"; "No es conveniente ni oportuno pero tampoco se puede decir que no"; “Oponerse a la instalación de una imagen 
de la Virgen María resulta un acto de intolerancia jacobina"; "El espacio público debe mantener la neutralidad. Debe ser como la escuela, laica, gratuita y obligatoria". Todas estas fueron afirmaciones pronunciadas, entre tantas otras, por los diferentes ediles. ¿Tendría la posibilidad la Virgen María de mirar definitivamente al mar en la misma Rambla que Iemanjá? Ante la ausencia de reglamentos específicos sobre el uso de los espacios públicos surgían cuestiones a futuro, en el sentido de establecer pautas claras para esto. Incluso existen algunas tentativas parlamentarias de encaminar procedimientos específicos de regulación de las instituciones religiosas, algo inexistente hasta ahora en el Uruguay y sobre lo cual Emerson Giumbelli (2016) ha producido un interesante marco comparativo entre Argentina, Uruguay, Brasil y México. Lo cierto es que la propuesta encaminada por el intendente Daniel Martínez fue rechazada por unanimidad por su fuerza política y apoyada también por unanimidad por la oposición. Incluso fue apoyada por el edil votado por el Frente Amplio y ahora independiente, lo que hizo que la votación terminara con 17 votos en contra de la instalación de la Virgen María en la Rambla y 14 votos a favor de la misma.

Algunos argumentos de quienes votaron a favor apuntaban a la laicidad positiva, a los valores que representa la imagen de María, al anticlericalismo, jacobinismo y acción discriminatoria por parte del Frente Amplio. Quienes votaron en contra argumentaron a favor de la laicidad, entendida no en forma positiva sino como simple neutralidad. Algunos expresaron que votaron en contra, pero no en contra de la imagen o en contra de nadie sino "a favor de todos". Otros, como el ex intendente de Montevideo, Mariano Arana (FA), declararon que votaron en contra por disciplina partidaria. Algunos días después de la votación Arana se mostró arrepentido de haber votado en contra. Cabe recordar que durante su gobierno en la Intendencia de Montevideo se había inaugurado, el 2 de febrero de 2005, el Espacio Libre Diversidad Sexual, en la Ciudad Vieja de Montevideo, con un monolito que homenajea a la comunidad LGBTI y una placa que dice: "Honrar la diversidad es honrar la vida. Montevideo por el respeto a todo género de identidad y orientación sexual". Pero lo de la Virgen, era la crónica de una muerte anunciada.

"Viva la laicidad"; "Viva el Estado laico"; "Viva Batlle"; "Viva la Virgen María"; "Viva la Junta Departamental de Montevideo". Esos fueron los vivas, los gritos que se sucedieron inmediatamente después de conocer el resultado de la votación en la JDM. Se hizo alusión a que las personas pasan pero las religiones 
siguen. Fue un rotundo jaque a la Virgen María y a la colectividad católica. Algunos insistieron en que continuarían dando batalla. Que la Virgen María se instalará en algún lugar de Montevideo. En próximas legislaturas seguirán dando batalla. Algún católico pasó a saludar a quienes defendían el NO en las barras, dándoles la mano y felicitándolos por la victoria. Alguno se negó a darle la mano. Los católicos se fueron sin poder tragar muy bien todo lo sucedido. Algunos decepcionados, otros con fuerzas redobladas para continuar lo que ellos entienden como una batalla. Sea como sea, la Junta Departamental de Montevideo jaqueó a la Virgen María. Lo que no sabemos es si el jaque es mate o no.

\section{Laicidad por todos lados}

En otros ámbitos, como la educación, el tema de la laicidad también estuvo en primera plana en los últimos meses en el Uruguay. Se destacan dos episodios que involucran temas de sexualidad y aborto. Uno relacionado al lanzamiento de la "Propuesta didáctica para el abordaje de la educación sexual en Educación Inicial y Primaria", publicado en 2017 por el Consejo de Educación Inicial y Primaria (CEIP) de la Administración Nacional de Educación Pública (ANEP), cuyas controversias en relación a su contenido están en plena disputa. Otro episodio que activó las alarmas de la laicidad fue un hecho registrado en la ciudad de Salto, del que se han manejado informaciones muy diversas y encontradas, donde una charla sobre el aborto impartida por mujeres católicas a estudiantes de secundaria, acabó con la separación provisoria del cargo de la directora del liceo $\mathrm{N}^{\circ} 1$ de esa ciudad. La complejidad y su actual discusión pública de estos temas, hacen que estos asuntos queden pendientes de análisis en una futura publicación. Lo que quiero decir aquí es que los dos episodios mencionados han terminado de poner en boca de muchos el tema de la laicidad en el Uruguay. Si alguna vez se dijo que el tema en Uruguay se reducía en última instancia a un debate de elites (lo cual, en buena medida, es cierto), los ejemplos que he mostrado a lo largo de este artículo, que incluye estos últimos dos, han hecho que cada vez sea más relevante y masiva la discusión y el debate en torno a la temática. Los dos últimos casos mencionados, en los que no profundizo aquí, tienen como paño de fondo, una vez más, 
a los sensores de la laicidad y sus réplicas. Con relación a la publicación de la "guía de sexualidad" y el caso del liceo de Salto, el arzobispo Sturla ha sido un fuerte crítico tanto de la publicación, como del procedimiento llevado adelante en el caso del liceo y ha insinuado en medios de prensa que las medidas adoptadas por el gobierno responden a las de regímenes totalitarios. Con relación a la guia de sexualidad, la propia Iglesia Católica ha implementado una serie de cursos sobre el tema que ofrece, en palabras de Sturla, "desde una perspectiva laica" a educadores. Algunas personas también se han manifestado públicamente en repudio de la "guía" al considerar que atenta contra principios de autonomía de educación por parte de los padres e imposición de valores cuya educación caben a la esfera privada y no a la escuela. La "propuesta didáctica" sugiere una deconstrucción de las definiciones dominantes sobre sexualidad y género, plantea nuevas definiciones y sugiere actividades a realizar en las aulas que incluyen la problematización de los estereotipos y roles de género, el trabajo con el cuerpo, etc. Entre otras actividades, se sugieren algunas que incluyen, por ejemplo, "Sacarse las medias y tocar con los pies: trozos de alfombra, piedritas, los pies de su compañero/a, etc.; Hacer cosquillas en los pies al otro/a; Hacer un masaje en los hombros, la espalda, los brazos y las manos, sintiendo las partes 'blandas' y las 'duras' del cuerpo del/la compañero/a.; Acariciar el pelo de su compañero/a" (CEIP, 2017, p. 70). Los meandros y matices de estos episodios son grandes y la polémica está en pleno vigor. Desde filas neopentecostales, incluso, el mencionado pastor Jorge Márquez, suegro del diputado Dastugue se ha expresado públicamente en contra de las políticas de educación sexual impulsadas por el gobierno, que según Márquez “impulsan el sexo con menores y animales". Estas afirmaciones le han costado recientes intimaciones por parte de sectores del Frente Amplio y el colectivo Ovejas Negras (con apoyo de varias otras organizaciones sociales, de estudiantes y profesionales) para que Márquez se retracte, o de lo contrario, llevar el caso a la justicia. Por su parte, el diputado Dastugue ha expresado públicamente que no hubo violación a la laicidad en el caso del liceo de Salto. Episodios como estos han llevado también a la crítica del modelo de laicidad que impera en el sistema educativo, ya que se entiende que el sistema de educación pública excluye la posibilidad de la formación religiosa, debiendo, quienes quieran optar por esta posibilidad, recurrir al sistema privado. El investigador Pablo da Silveira (2012), por ejemplo, es un 
interesante representante de una posición sobre la laicidad y la libertad de enseñanza que incluye la posibilidad de la educación religiosa dentro del sistema de educación pública.

\section{Conclusiones}

Hemos visto hasta aquí una serie de ejemplos de situaciones recientes en el Uruguay en las que de alguna $\mathrm{u}$ otra manera se han puesto de manifiesto las tensiones entre diferentes concepciones religiosas y morales. En lo que respecta a la desprivatización de lo religioso, los ejemplos quizá acompañan las tendencias regionales y globales a la cada vez mayor preponderancia de los aspectos religiosos en la vida pública y política de los Estados, como viene siendo señalado hace tiempo. En este sentido, Uruguay no se queda por fuera de estos movimientos. Lo que sí parece ser una especificidad de este país son las formas particulares en las que este tipo de tensiones son articuladas en el marco de las múltiples acepciones de la idea de laicidad que están en permanente pugna.

Así, hemos visto que desde las propias instituciones religiosas y políticas, las formas de interpretar la ecuación de la laicidad entre igualdad y diversidad, son variadas. Si por un lado resulta más notoria una acepción en términos de "laicidad positiva" proveniente de sectores más cercanos a la Iglesia Católica, con miras a dotar de mayor protagonismo en la vida social a esta institución, algunas iglesias protestantes históricas tienen mayores reparos en cuanto a temas específicos como la presencia de símbolos religiosos en el espacio público. De modo semejante, algunas expresiones de dirigentes afroumbandistas también evidencian concepciones diferentes del concepto de laicidad, apuntando, más allá de la "neutralidad", a la necesidad de las reparaciones históricas y de dar atención a las poblaciones y manifestaciones culturales históricamente subalternados. En el caso neopentecostal, las asociaciones explícitas entre iglesias y partidos políticos parece evidenciarse, como también en el caso que hemos visto del grupo Atabaque. Por otra parte, desde filas masónicas y asociaciones de Libre Pensamiento, surgen las posturas más “republicanas" (en el sentido dado por Maclure y Taylor a este régimen de laicidad) de la laicidad entendida en tanto completo abstencionismo por parte del Estado en materia 
religiosa. Vemos entonces con claridad las diferentes posturas en torno a la laicidad en Uruguay, tal como las ha tipificado Da Costa (2009). No resulta tarea sencilla alcanzar un acuerdo acerca de lo que se entiende por laicidad en Uruguay. Si bien en el plano académico prevalecen las referencias a ciertos autores comunes que dominan los debates mundiales en torno al tema, tampoco es necesariamente sencilla la clara separación entre las esfera académica y la de las propias acepciones individuales de los investigadores.

Es evidente que lo religioso ha pasado a tener un lugar de mayor relevancia en la vida política de los uruguayos. Pero no necesariamente porque ahora lo religioso sea más relevante que en otros momentos, sino porque se están viviendo escenarios en los que, a través de las identificaciones religiosas, están siendo interpeladas en la arena pública uruguaya las posibilidades de autoidentificación de los diferentes sectores que componen el tejido social. Las posibilidades de poner en tensión las identificaciones, valores y prácticas de las diferentes colectividades en la arena pública reflejan a su vez una ampliación de las libertades para hacerlo, lo cual es reflejo de dos procesos: uno de desecularización, y otro de disputa por el concepto y modelo de laicidad que se quiere para el país. Esto último a su vez, muestra la relevancia académica, social y política que adquiere la laicidad en Uruguay. Debemos considerar también que las alteridades no pasan únicamente a través del vector religioso. El Uruguay, en este mismo período de tiempo analizado aquí, ha recibido importantes movimientos en lo que respecta a la inmigración. La laicidad, entendida en su concepción más amplia que trasciende lo estrictamente jurídico en tanto separación de las iglesias del Estado, responde también a la libertad de conciencia. En ese sentido, poner sobre la mesa de discusión y normalizar los usos de distintas sustancias psicoactivas (me refiero particularmente al caso de la marihuana, fuerte política pública nacional en materia de drogas), es, también, una forma de profundizar en la libertad de conciencia. En algunos temas se ha avanzado más que en otros hacia la ampliación de derechos y reconocimientos. Un asunto pendiente, por ejemplo, sigue siendo el reconocimiento y la profundización en relación a los asuntos étnicos. Disputas de colectividades charrúas, aunque se ha avanzado, siguen estando pendientes. Y esto también es libertad de conciencia y por lo tanto laicidad (entendida en su sentido más amplio). Pues, en definitiva, pensar únicamente la laicidad en términos de los vínculos entre instituciones 
religiosas y el Estado responde a una visión estrecha de las formas posibles de entender las autodidentificaciones y las formas en las que se ponen de manifiesto diferentes aspectos de la vida social, incluso la religiosa. Por ejemplo, algunos argumentos en contra de la instalación de la virgen maría en la rambla de Montevideo apuntaban, no al hecho en sí mismo de ese u otro monumento, sino al hecho de que de esa forma de expresar la identificación, a través de un símbolo, y querer situarlo en el espacio público de forma permanente, atentaba de algún modo contra otras formas de vivir lo religioso en las que el ícono no es un asunto a considerar. El símbolo materializado es identificación y relación, pero es también poder. En el caso concreto de la Iglesia Católica, lo que pueda haber sido visto como un ataque explícito a esa colectividad en el caso de la negativa a la instalación de la imagen de la virgen María en la rambla (anticlericalismo, jacobinismo) ha sido argumentado también en el sentido de que ese sector de la población ya cuenta, por ejemplo, con una enorme cruz en la intersección de las avenidas más transitadas de la capital, una cruz de las dimensiones del obelisco, ubicada a pocos metros de este símbolo patrio. Incluso, y como ha sido expresado, por ejemplo, por metodistas, la presencia de la cruz en la vía pública podía ser entendida (aunque recordatoria de la visita del papa) en tanto símbolo ecuménico para todos los cristianos, característica que dejó de tener desde el momento en que la estatua de Juan Pablo II fue trasladada a sus pies en 2005, asociando explícitamente el símbolo a la colectividad católica.

$\mathrm{Si}$ bien es preciso apuntar a las especificidades del concepto de laicidad y sus sentidos más restrictos (separación de iglesias y Estado), este, a su vez, apunta a una conceptualización de las ideas asociadas a él, es decir, a una concepción amplia del término donde la laicidad desborda lo estrictamente jurídico y específicamente vinculado a lo religioso para convertirse en un elemento en disputa por la ampliación de identificaciones y presencia pública en clave democrática; lo cual, en términos analíticos, nos aproxima más a la idea de (des)secularización, pero no solo de los aspectos religiosos sino de los marcadores identificatorios en modo general. La institución Iglesia Católica es lo más claramente definible y asociable a un sentido estrecho de laicidad, pero luego se desprenden las ideas de Iglesia y Religión, cada uno de ellos incorporando grados de complejidad al asunto. Incluso, podríamos limitarnos a asociar estos términos en sus sentidos "clásicos", este último contemporáneo al de laicidad. 
Pero lo cierto es que estos mismos conceptos han sufrido transformaciones importantes que hacen que, por ejemplo, se vaya a buscar mucho más el hecho religioso "fuera de las instituciones religiosas". Y si entonces la laicidad refiere también a la "libertad de cultos" y a resolver la ecuación igualdad-diversidad, es imperioso profundizar las formas en las que se expresan los mecanismos de identificación y de producción de diferencias para comprender el mayor alcance que el concepto de laicidad puede adoptar. Incluso, desde formas de concebir algo "parecido a la laicidad" desde perspectivas diferentes a aquellas herederas de la modernidad secularizadora, es decir, desde tradiciones no modernas donde "religión" y "cultura" entran en complejos enriedos. El concepto de laicidad debe mucho a la historia particular de los vínculos modernos entre Iglesia Católica y Estado. Por otra parte, entendida en su sentido más amplio posible, la laicidad conduce a la inclusión de perspectivas que relativicen la hegemonía del propio concepto, dando lugar, justamente, a las libertades plenas de conciencia, es decir, de formas de ver el mundo. Mientras tanto, la multiplicidad de perspectivas y discusiones que se están planteando en Uruguay y que este texto esbozó, dan cuenta de que la laicidad es un tema de gran relevancia para los uruguayos. El asunto sigue siendo si las acepciones históricas dominantes del concepto de laicidad en tanto absoluta neutralidad y abstencionismo por parte del Estado en materia religiosa han dado buenos frutos y si puede seguir dándolos o no. Hasta allí el resultado podría considerarse satisfactorio en el Uruguay. El desafío estará en ver de qué forma esa neutralidad puede dar lugar a las cada vez mayores demandas por el espacio público de parte de las diferentes colectividades. No es casualidad que la explosión pública de la temática vaya de la mano de momentos específicos en la historia de las relaciones entre católicos y masones, de reclamos por reparaciones históricas, de disputa por el espacio público, de vínculos entre religiosos y políticos, etc. La laicidad opera entonces, en Uruguay, como un marco discursivo común en permanente disputa, una suerte de valor supremo regulador de la vida en sociedad. Un desafío para la laicidad es resolver las formas en que la pluralidad y diversidad de "libertades" entran a la disputa pública por las identidades. Si bien la laicidad es entendida en el ámbito académico como una forma particular en la que se puede desarrollar un proceso de secularización, y estos términos quedan claramente diferenciados, no necesariamente sucede lo mismo desde filas políticas, sociales o religiosas. A su vez, estas "esferas" no son tan 
fácilmente delimitables. Susana Andrade, por ejemplo, ¿es más religiosa que política o viceversa? En el ámbito estrictamente académico también es posible encontrar "bandos", más allá de que prevalezcan criterios académicos de argumentación y análisis. Néstor da Costa, por ejemplo, de la Universidad Católica, y retomando su clasificación de las posturas en torno a la laicidad, afirma que la posición de la laicidad intransigente "es probablemente la más visible en el debate público, y ha sido expresada por personalidades en las altas esferas de la educación y de la Universidad de la República, así como por connotados integrantes de la masonería" (Da Costa, 2009, p. 147). La postura negadora, por otra parte, es minoritaria según Da Costa (2009, p. 147) y “está más asociada a pequeños sectores del espacio católico", mientras que la posición plural "es probablemente la mayoritaria en la sociedad uruguaya, pero no dispone de organizaciones destinadas a promoverla y, por lo tanto, no figura claramente en los debates públicos". La posición del filósofo Da Silveira (que también es investigador y docente de la Universidad Católica) sobre las posibilidades de la inclusión de la educación religiosa en el sistema público muestran que más allá del estricto carácter académico de los diferentes investigadores, también existen diferencias o cercanías a ciertos ámbitos u otros que contribuyen a complejizar el debate.

Lo que podemos concluir de todo esto es que, como se ha dicho, la laicidad es un concepto de alta relevancia para la vida social, política y religiosa de los uruguayos. Un concepto, a su vez, que está en permanente disputa en la arena pública, lo cual, es precisamente un síntoma de la buena salud de la que goza. En nombre de la laicidad se lucha en Uruguay por cosas opuestas, lo cual puede ser síntoma de dos cuestiones diferentes: 1) un entreverado "griterío" (usando la expresión de Vázquez) donde se confunden las ideas de laicidad, secularización, libertad religiosa, libertad de conciencia, etc., y donde triunfa quien grite más fuerte; 2) una buena muestra del carácter democrático y de diálogo que se puede producir en torno al tema. En todo caso, la ampliación de quienes intervienen del debate es una señal de que bajo ese concepto hay mucho por dialogar aun. Mientras tanto, el Parlamento Nacional tiene pendiente la aprobación en Plenario del proyecto de ley propuesto por el senador Ope Pasquet, que declara el 6 de abril de cada año "Día de la laicidad". La fecha recuerda la sanción, el 6 de abril de 1909, de la ley 3.441 que dispuso que "queda suprimida toda enseñanza y práctica religiosa en las escuelas del Estado". 


\section{Referencias}

ANDRADE, S. Entre la religión y la política. Montevideo: La República, 2009.

ASOCIACIÓN CIVIL 20 DE SEPTIEMBRE. ¿A cual símbolo los chicos de 1er. año liceal juraron fidelidad?. 10 jun. 2014. Disponible en: <http://www.20desetiembre.org/ WP/2014/06/10/a-cual-simbolo-los-chicos-de-ler-ano-liceal-juraron-fidelidad/>. Acceso: 20 sept. 2017.

ASIAÍN, C. Religion and the secular state: Uruguayan report. In: DURHAM, W; MARTINEZ-TORRÓN, J. (Ed.). Religion and the secular state / La religion et l'État laïque: interim reports. [S.1.]: International Center for Law and Religion Studies, 2010. p. 767-789.

CAETANO, G. La instalación pública de la llamada “Cruz del Papa” y los perfiles de un debate distinto. In: GEYMONAT, R. (Coord.). Las religiones en Uruguay: algunas aproximaciones. Montevideo: La Gotera, 2003. p. 214-243.

CAETANO, G. Laicidad, ciudadanía y política en el Uruguay contemporáneo: matrices y revisiones de una cultura laicista. Cultura y Religión, v. 7, n. 1, p. 116-139, 2013.

CAETANO, G.; GEYMONAT, R. La secularización uruguaya (1859-1919). Montevideo: Taurus, 1997.

CAETANO, G. et al. El Uruguay laico: matrices y revisiones. Montevideo: Taurus, 2013.

CASANOVA, J. Rethinking secularization: a global comparative perspective. The Hedgehog Review, v. 8, n. 1/2, p. 7-22, 2006.

CEIP. Propuesta didáctica para el abordaje de la educación sexual en Educación Inicial y Primaria. Montevideo, 2017.

DA COSTA, N. A situação religiosa no Uruguai. In: ORO, A.; STEIL, C. (Org.). Globalização e religião. Petrópolis: Vozes, 1999. p. 93-101.

DA COSTA, N. Sobre la teoría de la secularización. Cuadernos del CLAEH, Montevideo, año 31, n. 96/97, p. 209-220, 2008.

DA COSTA, N. La laicidad uruguaya. Archives de sciences sociales des religions, n. 146, p. 137-155, 2009.

DA SILVEIRA, P. Libertad de enseñanza, libertad religiosa, secularización y laicidad: límites confusos y falsas asociaciones. Páginas de Educación, Montevideo, v. 5, n. 1, p. 17-36, 2012.

GIUMBELLI, E. O que é um ambiente laico? Espaços (inter)religiosos em instituições públicas. Cultura y Religión, v. 7, n. 2, p. 32-47, 2013. 
GIUMBELLI, E. Regulação do religioso. Discussões conceituais e panorama da situação em quatro países latino-americanos. Ciencias Sociales y Religión/Ciências Sociais e Religião, Porto Alegre, ano 18, n. 25, p. 14-37, dez. 2016.

GUIGOU, N. La nación laica: religión civil y mito praxis en el Uruguay. Montevideo: La Gotera, 2003.

GUIGOU, N. Religión y política en el Uruguay. Civitas, Porto Alegre, v. 6, n. 2, p. 43-54, 2006.

MACLURE, J.; TAYLOR, C. Laicidad y libertad de conciencia. Madrid: Alianza, 2011.

MONREAL, S. Libertad de enseñanza en Uruguay. Cuestionamientos y debates (1868-1888). Ariadna histórica: Lenguajes, conceptos, metáforas, v. 5, p. 127-150, $2016 \mathrm{.}$.

MONREAL, S. Católicos uruguayos reunidos y movilizados: las peregrinaciones a la Virgen del Verdún (1901-1941). Anuario de la Escuela de Historia, Rosario, n. 28, p. 91-118, 2016b.

PIOLI, U. La laicidad en peligro. Montevideo: Ediciones B, 2016.

PRESIDENCIA. República Oriental del Uruguay. Vázquez: laicidad, como garantía de respeto y pluralidad, es factor de democracia. 14 jul. 2005. Disponible en: <http:// archivo.presidencia.gub.uy/_web/noticias/2005/07/2005071404.htm>. Acceso: 20 sept. 2017.

RADIO CENTENARIO. Nicolás Cotugno agradeció a Tabaré Vázquez el polémico traslado de la estatua de Juan Pablo II de la iglesia del Opus Dei a la Av. 8 de Octubre y Bvar. Artigas donde se constituyó en un monumento público. 3 mayo 2005. Disponible en: <http://www. radio36.com.uy/entrevistas/2005/05/030505_bolioli.htm>. Acceso: 20 sept. 2017.

URUGUAY. Ley $n^{\circ}$ 9.943. Instruccion militar. Se da a los ciudadanos la obligacion de defender la Republica, determinandose como deben prepararse. Montevideo, 20 jul. 1940. Disponible en: <https://legislativo.parlamento.gub. uy/aresuelveref.aspx? LEY,9943//HTM $/ \&$ width $=800$ \&height $=600 \& h \mathrm{l}=$ en US1\&iframe=true\&rel=nofollow $>$. Acceso: 20 sept. 2017.

URUGUAY. Ley $n^{\circ} 15.870$. Papa Juan Pablo II. Se dispone que la cruz erigida con motivo de su visita, sea mantenida en su emplazamiento en calidad de monumento conmemorativo. Monteviseo, 22 jun. 1987. Disponible en: <https://legislativo.parlamento.gub.uy/temporales/leytemp5581748.htm>. Acceso: 20 sept. 2017.

Recebido: 30/09/2017 Aceito: 23/05/2018 | Received: 9/30/2017 Accepted:5/23/2018

Esta obra está licenciada com uma Licença Creative Commons - Atribuição 4.0 Internacional This work is licensed under a Creative Commons Attribution 4.0 International License. 